Check for updates
OPEN ACCESS

\section{Use of high dose cyproterone acetate and risk of intracranial meningioma in women: cohort study}

\author{
Alain Weill, ${ }^{1,2}$ Pierre Nguyen, ${ }^{2,3}$ Moujahed Labidi, ${ }^{4}$ Benjamin Cadier, ${ }^{1}$ Thibault Passeri, ${ }^{4}$ \\ Lise Duranteau, ${ }^{5}$ Anne-Laure Bernat, ${ }^{4}$ Isabelle Yoldjian, ${ }^{3}$ Sylvie Fontanel, ${ }^{6}$ Sébastien Froelich, ${ }^{4}$ \\ Joël Coste ${ }^{1,7}$
}

${ }^{1}$ Department of Public Health

Studies, French National Health Insurance, Paris, France Group, Saint-Denis, France Safety of Medicines and Health

Products (ANSM), Saint-Denis,

France

${ }^{4}$ Department of Neurosurgery, Lariboisière Hospital, AP-HP,

University of Paris, Paris, France

${ }^{5}$ Gynaecology Unit and Reference

Center for Rare Diseases of Genital Development, AP-HP,

University Paris Saclay, Bicêtre

Hospital, Le Kremlin-Bicêtre,

France

${ }^{6}$ Grand Est Regional Health Authority, Nancy, France

${ }^{7}$ Biostatistics and Epidemiology Unit, Cochin Hospital, AP-HP,

Paris, France

Correspondence to:

A Weill EPI-PHARE

Scientific Interest Group,

42 Bd de la Libération,

93200 Saint-Denis, France

alain.weill@assurance-maladie.fr

(ORCID 0000-0001-8687-9092)

Additional material is published online only. To view please visit

the journal online.

Cite this as: $B M / 2021 ; 372: n 37$ http://dx.doi.org/10.1136/bmj.n37

Accepted: 3 December 2020
${ }^{2}$ EPI-PHARE Scientific Interest

${ }^{3}$ French National Agency for the

\section{ABSTRACT}

OBJECTIVE

To assess the risk of meningioma associated with use of high dose cyproterone acetate, a progestogen indicated for clinical hyperandrogenism.

DESIGN

Observational cohort study.

SETTING

Data from SNDS, the French administrative healthcare database, between 2007 and 2015.

\section{PARTICIPANTS}

253777 girls and women aged 7-70 years living in France who started cyproterone acetate between 2007 and 2014. Participants had at least one reimbursement for high dose cyproterone acetate and no history of meningioma or benign brain tumour, or long term disease status. Participants were considered to be exposed when they had received a cumulative dose of at least $3 \mathrm{~g}$ during the first six months (139222 participants) and very slightly exposed (control group) when they had received a cumulative dose of less than $3 \mathrm{~g}$ (114555 participants). 10876 transgender participants (male to female) were included in an additional analysis.

MAIN OUTCOME MEASURE

Surgery (resection or decompression) or radiotherapy for one or more intracranial meningiomas.

RESULTS

Overall, 69 meningiomas in the exposed group (during 289544 person years of follow-up) and 20

\section{WHAT IS ALREADY KNOWN ON THIS TOPIC}

Cyproterone acetate is a synthetic progestogen with strong antiandrogen and antigonadotrophin effects

Since 2007, several case series of intracranial meningiomas have described patients who developed one or more meningiomas after using cyproterone acetate at doses of $25-100 \mathrm{mg}$ daily for $5-30$ years

The presence of progesterone receptors on meningiomas supports the biological plausibility of an association

\section{WHAT THIS STUDY ADDS}

This study confirms a strong and dose dependent association between use of high dose cyproterone acetate ( 25 or $50 \mathrm{mg} /$ day) in girls and women and meningioma treated by surgery or radiotherapy

The risk of meningioma in the group who used cyproterone acetate for 10-30 years was four participants per 1000 person years

Meningiomas located in the anterior skull base and middle skull base appeared to be specific to cyproterone acetate; the risk decreased after cyproterone acetate was discontinued meningiomas in the control group (during 439949 person years of follow-up) were treated by surgery or radiotherapy. The incidence of meningioma in the two groups was 23.8 and 4.5 per 100000 person years, respectively (crude relative risk 5.2, 95\% confidence interval 3.2 to 8.6; adjusted hazard ratio $6.6,95 \%$ confidence interval 4.0 to 11.1 ). The adjusted hazard ratio for a cumulative dose of cyproterone acetate of more than $60 \mathrm{~g}$ was 21.7 (10.8 to 43.5). After discontinuation of cyproterone acetate for one year, the risk of meningioma in the exposed group was 1.8-fold higher (1.0 to 3.2) than in the control group. In a complementary analysis, 463 women with meningioma were observed among 123997 already using cyproterone acetate in 2006 (risk of 383 per 100000 person years in the group with the highest exposure in terms of cumulative dose). Meningiomas located in the anterior skull base and middle skull base, particularly the medial third of the middle skull base, involving the spheno-orbital region, appeared to be specific to cyproterone acetate. An additional analysis of transgender participants showed a high risk of meningioma (three per 14460 person years; 20.7 per 100000 person years).

\section{CONCLUSIONS}

A strong dose-effect relation was observed between use of cyproterone acetate and risk of intracranial meningiomas. A noticeable reduction in risk was observed after discontinuation of treatment.

\section{Introduction}

Cyproterone acetate is a synthetic progestogen with a potent antiandrogen action. The drug has been approved in European countries by national marketing authorisation procedures since the 1970 s and is available on prescription under various trade names and dose strengths (1, 2, 10, 50, and 100 $\mathrm{mg}$ ). The indications for cyproterone acetate also vary considerably from one country to another. Cyproterone acetate is indicated in men (50 or $100 \mathrm{mg}$ ) with inoperable prostate cancer and paraphilias. In women, the $50 \mathrm{mg}$ dose is indicated for various disorders of the hirsutism or hyperandrogenism spectrum in 19 European countries, including France, Spain, Germany, Belgium, Poland, and the Netherlands. In other European countries, $10 \mathrm{mg}$ tablets are marketed and indicated for signs of androgenisation and certain forms of hirsutism (table 1 shows approved indications in women in Europe; supplementary material S1 shows approved indications in men in Europe). Cyproterone acetate is also used at a low dose of $2 \mathrm{mg}$ combined with $35 \mu$ g ethinylestradiol for the treatment 
of acne related to androgen sensitivity or hirsutism in women of reproductive age, and at a dose of $1 \mathrm{mg}$ in combination with estradiol valerate $2 \mathrm{mg}$ as hormone replacement therapy.

Since 2007, several case series of both men and women have reported meningioma associated with prolonged use (5-30 years) of high dose cyproterone acetate (25-100 mg daily). ${ }^{1-11}$ The labelling of cyproterone acetate $(10,50$, and $100 \mathrm{mg})$ was modified in 2009, ${ }^{12}$ and since 2011 and 2013 the labelling of both the brand name drug and generic drugs, respectively, indicate that meningiomas have been reported in people with prolonged use of cyproterone acetate. $^{13}$ A history or presence of meningioma now also constitutes a contraindication to use of cyproterone acetate. $^{1213}$

Two low powered epidemiological studies on the link between cyproterone acetate and meningioma have been published. One of the studies reported two men and two women with meningioma, corresponding to a relative risk of 11.4 (95\% confidence interval 4.3 to 30.8$).{ }^{14}$ The other study found an excess risk in men (four men with meningioma) with an odds ratio of 3.3 (1.0 to 10.6), but concluded that low dose cyproterone acetate was not associated with an increased risk of meningioma in women. ${ }^{15}$

We evaluated the real life impact of prolonged use of high dose cyproterone acetate on risk of meningioma in girls and women. Our secondary objectives were to evaluate the dose-effect relation, define the course of the risk of meningioma after discontinuation of cyproterone acetate, identify specific features of cyproterone acetate related meningiomas, measure the effective discontinuation rate for cyproterone acetate after treatment for meningioma, and estimate the number of meningiomas treated by surgery or radiotherapy that were attributable to use of cyproterone acetate in France. In an additional analysis, we evaluated the real life impact of prolonged use of high dose cyproterone acetate on risk of meningioma in transgender participants.

\section{Methods}

This cohort study used data from the French administrative health care database (SNDS, formerly SNIIRAM, established in 2006). We compared the incidence of treated meningioma (event of interest) in girls and women (age 7-70 years) who used high dose cyproterone acetate with the incidence in those who prematurely discontinued cyproterone acetate and were only very slightly exposed (control group).

The main study included a cohort of women who started high dose cyproterone acetate between 2007 and 2014, with follow-up to the end of 2015. Under optimal epidemiological conditions (new incident users with known cumulative doses over time), we tested the hypothesis of an association between exposure and risk of meningioma, and evaluated a possible dose-effect relation.

We also analysed a population of girls and women who were already using cyproterone acetate in 2006, and followed this cohort until the end of 2015. Based on the hypothesis of a causal association, we used this population to define the characteristics of cyproterone acetate related meningiomas and the number of meningiomas treated by surgery or radiotherapy that were attributable to cyproterone acetate use. This cohort comprised women who had continually used cyproterone acetate for a long period (more than eight years), although left censoring of data occurred because only cumulative doses since 2006 are known with certainty. We conducted a further analysis on a population of transgender participants (male to female) who started high dose cyproterone acetate between 2007 and 2017, with follow-up until the end of 2018.

\section{Data source}

SNDS covers the entire population of France-67 million residents. Each person is identified by a unique, anonymous number. Since 2006, SNDS has recorded information on all outpatient care (including drugs, imaging, and laboratory tests) and inpatient care (including diagnoses and procedures performed, coded according to the common classification of medical procedures-CCAM). The health expenditure for patients with long term diseases, such as cancer and diabetes, is fully reimbursed, and their diagnosis is recorded according to ICD-10 (international classification of diseases, 10th revision) codes. SNDS has been extensively used in France to conduct real life studies, especially on the use, safety, and efficacy

\begin{tabular}{|c|c|}
\hline Country & Approved indications in girls and women \\
\hline \multicolumn{2}{|l|}{ Cyproterone acetate $10 \mathrm{mg}$ tablets } \\
\hline $\begin{array}{l}\text { Austria, Belgium, Cyprus, Germany, Greece, Luxembourg, } \\
\text { Portugal }\end{array}$ & $\begin{array}{l}\text { Moderately severe signs of androgenisation, eg, moderately severe hirsutism, androgenetic alopecia, and acne and } \\
\text { seborrhoea. In moderately severe forms of acne and seborrhoea, supplementary cyproterone acetate tablets are } \\
\text { indicated when clinical features are refractory to other treatments and no satisfactory results have been achieved } \\
\text { with low dose cyproterone acetate and estradiol ( } 2 \mathrm{mg} / 0.035 \mathrm{mg}) \text { combination alone }\end{array}$ \\
\hline Netherlands & $\begin{array}{l}\text { Idiopathic hirsutism when other treatments have failed. Treatment of severe forms of acne when low dose } \\
\text { cyproterone acetate has not provided improvement }\end{array}$ \\
\hline \multicolumn{2}{|l|}{ Cyproterone acetate $50 \mathrm{mg}$ tablets } \\
\hline $\begin{array}{l}\text { Austria, Belgium, Bulgaria, Croatia, Czech Republic, } \\
\text { Estonia, Finland, Germany, Latvia, Lithuania, Luxembourg, } \\
\text { Netherlands, Romania, Slovakia, Slovenia, Spain, Poland }\end{array}$ & $\begin{array}{l}\text { Severe signs of androgenisation, eg, highly severe hirsutism, severe androgenetic alopecia, often attended by } \\
\text { severe forms of acne or seborrhoea }\end{array}$ \\
\hline France & $\begin{array}{l}\text { Severe non-neoplastic hirsutism (idiopathic, polycystic ovary syndrome), with a major impact on emotions and } \\
\text { social life }\end{array}$ \\
\hline Sweden & Pronounced hirsutism in women of childbearing age \\
\hline
\end{tabular}


of drugs. ${ }^{16-18}$ Many pharmacoepidemiological studies have been based on the use of this database. ${ }^{19-26}$ SNDS also contains sociodemographic data, and when applicable, the date of death. A limitation of the data source is that it does not provide any information about non-reimbursed drugs-over the counter drugs and drugs providing insufficient medical benefit, such as third generation drugs and the most recent combined oral contraceptives (since 2013), or low dose cyproterone acetate and oestrogen ( $2 \mathrm{mg} / 0.035$ $\mathrm{mg}$ ) combination pills.

\section{Study populations}

The main study included a cohort of girls and women who started cyproterone acetate and fulfilled the following criteria: they were covered by the national health insurance general scheme, including local mutualist sections (civil servants, local government officials, public hospital officials), $87 \%$ of the population living in France, were aged between 7 and 70 years at the time of starting cyproterone acetate, and were dispensed cyproterone acetate between 2007 and 2014, in the absence of any dispensing of cyproterone acetate in 2006. Participants who fulfilled the first two criteria but were dispensed cyproterone acetate in 2006 were included in a complementary cohort (cohort exposed in 2006).

\section{Exclusion criteria}

The following girls and women were excluded from the cohorts studied:

- Girls and women with a long term disease (including lupus, cancer, and all other chronic diseases with $100 \%$ national health insurance coverage) and long term disease status starting one month before cyproterone acetate was started, at the latest. This exclusion was justified because continuous treatment with $50 \mathrm{mg}$ cyproterone acetate daily can be proposed as a method of contraception in women with systemic lupus erythematosus or other chronic diseases (such as rheumatoid arthritis). In general, we excluded women with a serious illness (eg, cancer, neurological disease) that was likely to affect the risk of meningioma and especially the treatment of meningioma. We did not use this exclusion criterion for the analysis on transgender participants (male to female) because they are managed for sex reassignment surgery and psychiatric care, and sometimes have long term disease status (ICD-10 code F64.0) for this purpose.

- Women with a history of benign neoplasm of meninges, benign neoplasm of brain and other parts of the central nervous system, or neoplasm of uncertain or unknown behaviour of meninges (ICD-10 codes D32, D33, D42 as principal diagnosis, related diagnosis, or associated diagnosis during a hospital stay or as long term disease) between 1 January 2006 and the date of start of follow-up.

\section{Definition of exposure and follow-up}

Participants in the main study cohort were considered to be exposed when they had received a first prescription for cyproterone acetate between 1 January 2007 and 31 December 2014, and the cumulative dose was greater than or equal to $3 \mathrm{~g}$ (at least three standard packs of $20,50 \mathrm{mg}$ tablets) within the first six months of this first prescription. The study start date corresponded to the date of the first prescription for cyproterone acetate (index date). Follow-up began six months after the first prescription for cyproterone acetate. We compared this group of exposed participants with a control group who received a first prescription for cyproterone acetate between 1 January 2007 and 31 December 2014, and who rapidly discontinued treatment after having received a cumulative dose of less than $3 \mathrm{~g}$ (one or two standard packs) dispensed within the first six months after this first prescription.

\section{Main outcome}

The main outcome was neurosurgical resection, decompression, or radiotherapy for one or more intracranial meningiomas. The event of interest was identified by the combination of a first admission to hospital for meningioma coded as the principal diagnosis or related diagnosis according to ICD-10 as D32 benign neoplasm of meninges, with at least one surgical procedure for tumour resection or a list of codes likely to be used in meningioma surgery, or a stereotactic radiosurgery procedure, or a fractionated radiotherapy procedure (supplementary material S2).

\section{Follow-up}

All participants were followed until 31 December 2015 (end of study date) or until the first of the following events, whichever occurred first: event of interest; lost to follow-up, defined by a period of more than 24 months with no national health insurance reimbursement; for the control group, date of resumption of cyproterone acetate; for the exposed group, censorship after one year without a prescription for cyproterone acetate; or death.

We performed a sensitivity analysis in which participants could change treatment group, therefore corresponding to time dependent use of cyproterone acetate. Participants in the control group for whom a new prescription of cyproterone acetate was identified after the start of follow-up were switched to the exposed group. Participants in the exposed group who discontinued treatment for one year were switched to the discontinuation group.

Two other sensitivity analyses were conducted: analysis of the 2007-14 exposed or control group main cohort who were matched for age at initiation and duration of follow-up, and a nested case-control study on the 2007-14 main cohort.

\section{Covariables and confounding factors}

The following characteristics of women and their care pathways were also considered:

- Sociodemographic characteristics: age, complementary universal health insurance (CMUc: social 
welfare marker of deprivation, corresponding to free health insurance; it is attributed under certain conditions of residence and resources when the annual income in 2015 was less than €8645 (£7740; \$10 500) for a single person and €12967 for a couple. These income levels are below the poverty threshold), and region of residence.

- The first prescriber's specialty (identified in the database): gynaecologist, dermatologist, endocrinologist, general practitioner, or other.

- Coprescription of oestrogens.

- Presumed context of prescription:

- Reimbursed laser hair removal procedure, treatment for hirsutism, admission to hospital with a diagnosis of hirsutism, laboratory assay corresponding to the diagnosis of hirsutism (follicle stimulating hormone, luteinising hormone, testosterone, docosahexaenoic acid), pelvic ultrasonography.

- History of specific treatment for acne (drugs with ATC (anatomical therapeutic chemical) codes D10AB, D10AD01, D10AD02, D10AD03, D10AE01, D10AF02, D10AF52, D10AX, D10AX30, D10BA01, D10BX).

- Gynaecologist, dermatologist, or endocrinologist consultations.

- The context of prescription of cyproterone acetate was evaluated as a function of health care use. Supplementary material S3 presents the algorithms used. Schematically, possible prescription for hirsutism was adopted on the basis of admission to hospital or long term disease for hirsutism, or laser hair removal reimbursed by national health insurance (indicated for hirsutism), or concomitant or previous drug treatment for hirsutism (such as finasteride or spironolactone; supplementary material S4), or a laboratory investigation (follicle stimulating hormone, luteinising hormone, testosterone, docosahexaenoic acid), and abdominopelvic ultrasonography and follow-up compatible with hirsutism.

- Possible prescription for acne was adopted or considered, in the absence of hirsutism, on the basis of a drug treatment for acne (such as isotretinoin, topical erythromycin).

\section{Statistical analyses}

We used Cox proportional hazards models to compare the incidence of events between the various groups: exposed and control group for the main analysis; and exposed, control group, and discontinuation group for the sensitivity analysis. We adjusted for baseline characteristics (age, expressed as a continuous variable, CMUc, initial prescriber's specialty, indication, coprescription of oestrogens) by only maintaining those variables statistically significantly associated with the development of meningioma and related to the dose of cyproterone acetate. Cumulative dose and age were considered to be time dependent variables in the analysis.
We used conditional logistic regression for meningioma according to use of cyproterone acetate, with matching for age at initiation and duration of follow-up, and for the nested case-control study on the main cohort. Results are presented according to the anatomical location of the meningioma and the initial CCAM classification, categorised into six groups (anterior skull base; middle skull base; posterior skull base; convexity, not involving the dural venous sinuses; convexity, involving the dural venous sinuses; falx cerebri and tentorium). Supplementary material S2 also presents a second more precise classification into 16 groups. Data were analysed with SAS Enterprise Guide version 4.3 software.

\section{Regulatory and ethical aspects}

SNDS is a strictly anonymous database, comprising all reimbursement data derived from mandatory health insurance, particularly data derived from processing of electronic or paper healthcare reimbursement forms and data derived from healthcare institutions through the national hospital discharge database (Programme de Médicalisation des Systèmes d'InformationPMSI). This study was conducted in the context of the specific CNIL framework agreement: CNIL decision DE-2011-078 (5 September 2011) authorising the French National Health Insurance (Caisse nationale de l'assurance maladie-CNAM) to process personal health data in retrospective cohort studies designed to describe possible statistical associations between the use of a drug product and the development of a disease or death. CNAM or ANSM (French National Agency for Medicines and Health Products Safety) staff, personally authorised to access SNDS, extracted and analysed the data.

\section{Patient and public involvement}

No patients were involved in setting the research question or the outcome measures, nor were they involved in developing plans for recruitment, design, or implementation of the study. No patients were asked to advise on interpretation or writing up of results.

\section{Results}

After we excluded girls and women in line with the protocol (fig 1), including 12612 people with long term diseases (supplementary material S5), the main study cohort comprised 253777 participants: 13922 (54.9\%) in the exposed group and 114555 (45.1\%) in the control group.

Table 2 shows the characteristics of the participants at cohort entry. Mean age was 29.4 years and more than $40 \%$ of the cohort were younger than 25 years. The initial prescriber was a gynaecologist for more than half of the participants (56.7\%). About 30\% had undergone laboratory investigations compatible with hirsutism and less than $40 \%$ had undergone pelvic ultrasonography, which is essential for the investigation of hirsutism. The presumed context of prescription for cyproterone acetate was therefore difficult to define: according to the algorithms used in 


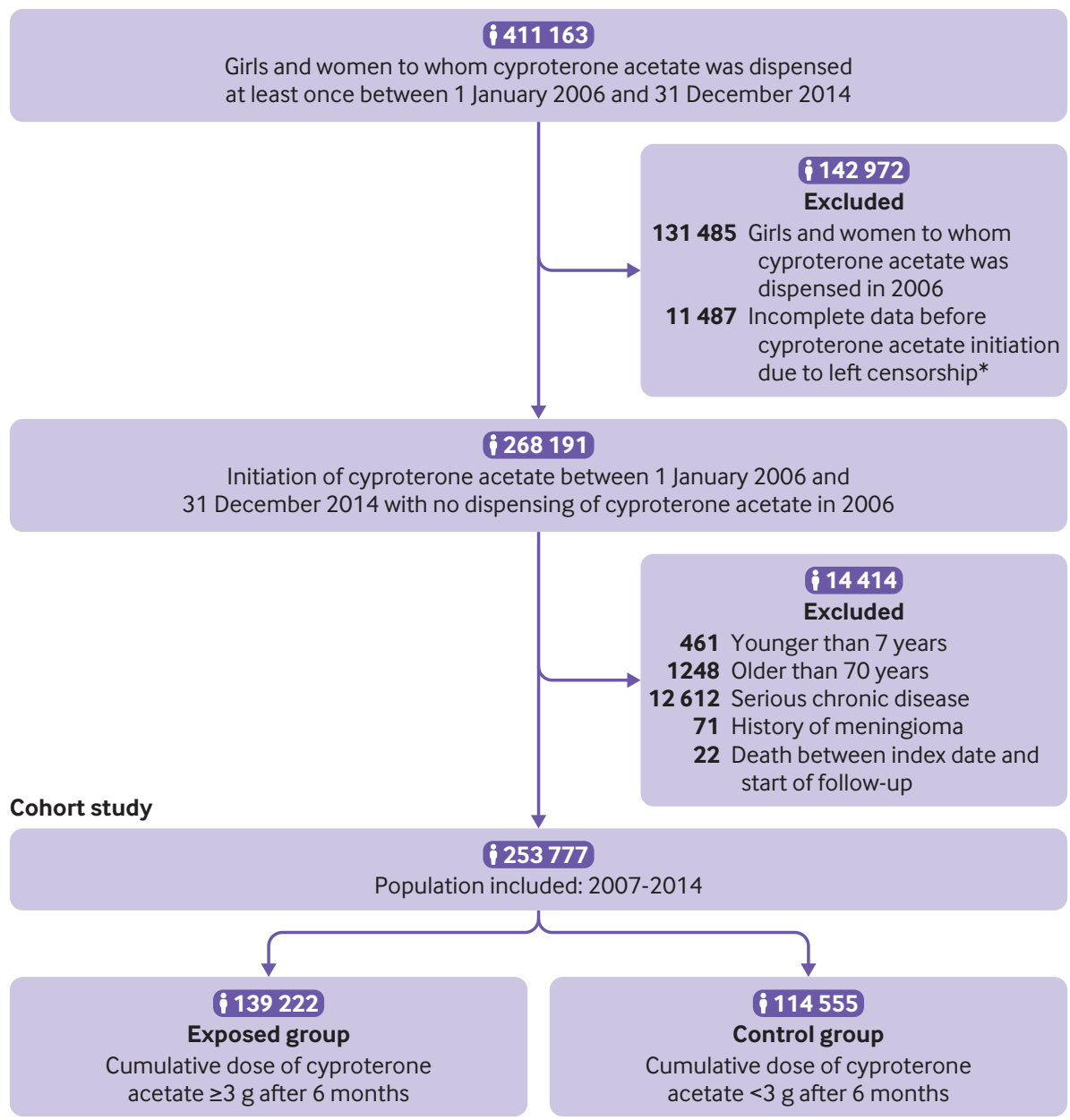

Fig 1 | Flowchart of main cohort (2007-14). *Possible causes: recent immigration, return to France after several years abroad, complete absence of any healthcare utilisation, and poor knowledge of care pathway

this study, $31.6 \%$ of prescriptions could correspond to the treatment of acne without hirsutism and 13.1\% of prescriptions were compatible with management of hirsutism. More than $55 \%$ of prescriptions were not associated with any markers for acne treatment, or treatment or investigation of hirsutism. Overall, on inclusion, the exposed population was similar to the control group population. In both groups, treatment was predominantly initiated by gynaecologists (55.9\% $v$ 57.8\%). Prescriptions for possible hirsutism were slightly more common in the exposed group-laboratory screening for possible hirsutism was performed in $36.0 \%$ and $23.2 \%$ of participants, respectively; and follow-up compatible with hirsutism was identified in $15.8 \%$ compared with $9.8 \%$ of participants, respectively (table 2). Drug coprescriptions during the 30 days after initiation of cyproterone acetate were similar in the two groups (supplementary material S6), with the exception of oestrogens (55.6\% $v 33.5 \%)$. The mean duration of follow-up was 2.1 years for exposed participants and 3.8 years for control group participants.

Age at the start of treatment was strongly associated with risk of meningioma, with a hazard ratio compared with the reference group (age 25-34 years) of 0.2 (95\% confidence interval 0.0 to 1.2$)$ for participants younger than 25 years, 10.4 (4.8 to 22.5) for participants aged 45-54 years, and 42.3 (15.9 to 112.7) for those aged 65 years and older. In view of the major impact of age on risk of meningioma, the other patient characteristics were all tested after adjustment for age. CMUc, the context of prescription, and the prescriber's specialty were not associated with risk of meningioma. In contrast, coprescription of oestrogens was significantly associated with risk of meningioma, with a hazard ratio of 1.6 (1.1 to 2.4; supplementary material S7).

\section{Risk of meningioma associated with cyproterone acetate}

Sixty nine meningiomas in the exposed group and 20 in the control group were treated by surgery or radiotherapy. The incidence of meningioma in the two groups was 23.8 per 100000 person years and 4.5 per 100000 person years, respectively; that is, a crude relative risk of 5.2 (95\% confidence interval 3.2 to 8.6) and an adjusted hazard ratio of 6.6 (95\% confidence interval 4.0 to 11.1 ; table 3 ). Analysis according to the cumulative dose of cyproterone acetate showed a dose-effect relation, with a higher risk associated with 


\begin{tabular}{|c|c|c|c|c|}
\hline $\begin{array}{l}\text { Characteristics, follow-up, and reasons for } \\
\text { exclusion }\end{array}$ & Total $(n=253777)$ & $\begin{array}{l}\text { Exposed } \\
(n=139222,55 \%)\end{array}$ & $\begin{array}{l}\text { Control group } \\
(n=114555,45 \%)\end{array}$ & P value \\
\hline \multicolumn{5}{|l|}{ Start of treatment } \\
\hline Mean (SD) age (years) & $29.4(10.9)$ & $29.1(10.9)$ & $29.9(10.9)$ & $<0.001$ \\
\hline Median (interquartile range) age (years): & $27(21-37)$ & $27(20-36)$ & $28(21-37)$ & - \\
\hline $7-24$ & $101655(40.1)$ & $58430(42.0)$ & $43225(37.7)$ & - \\
\hline $25-34$ & $76056(30.0)$ & $40367(29.0)$ & $35689(31.2)$ & - \\
\hline $35-44$ & $49732(19.6)$ & $26681(19.2)$ & $23051(20.1)$ & - \\
\hline $45-54$ & $20349(8.0)$ & $10587(7.6)$ & $9762(8.5)$ & - \\
\hline$\geq 55$ & $5985(2.4)$ & $3157(2.3)$ & $2828(2.5)$ & $<0.001$ \\
\hline \multicolumn{5}{|l|}{ Year of start of treatment } \\
\hline 2007 & 39481 (15.9) & $21361(15.3)$ & $18120(15.8)$ & - \\
\hline 2008 & $36403(14.3)$ & $19543(14.0)$ & $16860(14.7)$ & - \\
\hline 2009 & $33427(13.2)$ & $18273(13.1)$ & $15154(13.2)$ & - \\
\hline 2010 & $33752(13.3)$ & $18383(13.2)$ & 15369 (13.4) & - \\
\hline 2011 & $30120(11.9)$ & $16390(11.8)$ & $13730(12.0)$ & - \\
\hline 2012 & $26539(10.5)$ & $14313(10.3)$ & $12226(10.7)$ & - \\
\hline 2013 & $31327(12.3)$ & $17905(12.9)$ & $13422(11.7)$ & - \\
\hline 2014 & $22728(9.0)$ & $13054(9.4)$ & $9674(8.4)$ & $<0.001$ \\
\hline \multicolumn{5}{|l|}{ CMUc beneficiary* } \\
\hline Yes & $18499(7.3)$ & $9093(6.5)$ & $9406(8.2)$ & - \\
\hline No & $235278(92.7)$ & $130129(93.5)$ & $105149(91.8)$ & $<0.001$ \\
\hline \multicolumn{5}{|l|}{ Specialty of initial prescriber } \\
\hline Gynaecologist & $144018(56.7)$ & $77816(55.9)$ & $66202(57.8)$ & - \\
\hline Dermatologist & $29289(11.5)$ & $12944(9.3)$ & $16345(14.3)$ & - \\
\hline Endocrinologist & $25557(10.1)$ & $18171(13.1)$ & $7,386(6.4)$ & - \\
\hline General practitioner & $46412(18.3)$ & $25440(18.3)$ & $20972(18.3)$ & - \\
\hline Other & $8499(3.3)$ & $4850(3.5)$ & $3649(3.2)$ & - \\
\hline Missing & $2(0.0)$ & $1(0.0)$ & $1(0.0)$ & $<0.001$ \\
\hline \multicolumn{5}{|l|}{ Associated procedures or caret } \\
\hline Hospital treatment with diagnosis of hirsutism & $3911(1.5)$ & $3017(2.2)$ & $894(0.8)$ & $<0.001$ \\
\hline Reimbursement for laser hair removal & $2194(0.9)$ & $1641(1.2)$ & $553(0.5)$ & $<0.001$ \\
\hline Laboratory tests (FSH, LH, testosterone, DHA) & $76729(30.3)$ & $50104(36.0)$ & $26625(23.2)$ & $<0.001$ \\
\hline Pelvic ultrasonography & $98206(38.8)$ & $56278(40.4)$ & $41928(36.6)$ & $<0.001$ \\
\hline Anti-acne drugs & $94379(37.2)$ & $50449(36.2)$ & $43930(38.4)$ & $<0.001$ \\
\hline \multicolumn{5}{|l|}{ Coprescription of oestrogens } \\
\hline Yes & $115700(45.6)$ & $77387(55.6)$ & $38313(33.5)$ & - \\
\hline No & $138077(54.4)$ & $61835(44.4)$ & $76242(66.6)$ & $<0.001$ \\
\hline \multicolumn{5}{|l|}{ Duration of follow-up (years) } \\
\hline Mean (SD) & $2.9(2.3)$ & $2.1(1.6)$ & $3.8(2.6)$ & $<0.001$ \\
\hline Median (interquartile range): & $2.0(1.0-4.4)$ & $1.4(1.0-2.5)$ & $3.7(1.5-6.1)$ & $<.001$ \\
\hline$<2$ & $128428(50.6)$ & $92024(66.1)$ & $36404(31.8)$ & - \\
\hline$\geq 2$ to $<5$ & $73064(28.8)$ & $36820(26.4)$ & $36244(31.6)$ & - \\
\hline$\geq 5$ & $52285(20.6)$ & $10378(7.5)$ & $41907(36.6)$ & $<0.001$ \\
\hline Person years & 729493 & 289544 & 439949 & - \\
\hline \multicolumn{5}{|l|}{ Reason for exclusion from cohort } \\
\hline 31 December 2015 & $117788(46.4)$ & $32143(23.1)$ & $85645(74.8)$ & $<0.001$ \\
\hline Death & $242(0.095)$ & $77(0.055)$ & $165(0.144)$ & $<0.001$ \\
\hline Event of interest & $89(0.0)$ & $69(0.0)$ & $20(0.0)$ & $<0.001$ \\
\hline Discontinuation of drug for exposed group & - & $106933(76.8)$ & - & - \\
\hline Lost to follow-up & - & - & $3429(3.0)$ & - \\
\hline New prescription for control group & - & - & $25296(22.1)$ & - \\
\hline
\end{tabular}

a higher cumulative dose. The hazard ratio was not significantly different from 1 for exposure to less than $12 \mathrm{~g}$ of cyproterone acetate, and it rapidly increased for higher cumulative doses: 11.3 (5.8 to 22.2) for 36-60 $\mathrm{g}$ and 21.7 (10.8 to 43.5) for $60 \mathrm{~g}$ or higher (table 3).

The risk of meningioma after discontinuation of cyproterone acetate for one year was found to be 1.8-fold higher (95\% confidence interval 1.0 to 3.2 ) than the risk related to the control group. The risk was observed to be 4.2-fold higher (2.2 to 8.0) when the cumulative dose of cyproterone acetate before discontinuation was $12 \mathrm{~g}$ or higher (supplementary material S8).

In the sensitivity analysis of the main cohort, when matched for age and duration of follow-up, the crude odds ratio was 8.3 (95\% confidence interval 3.9 to 17.2) and the adjusted odds ratio was 8.0 (3.6 to 17.5; supplementary material S9 and S10). Finally, a nested case-control analysis that used conditional logistic regression showed a crude odds ratio of 4.7 (2.9 to 7.8) 
and an adjusted odds ratio of 5.8 (3.4 to 9.9) with a dose-effect relation (supplementary material S11).

In the cohort of participants already using cyproterone acetate in $2006(n=123997)$, the mean age was 32.1 years (supplementary material S12 and S13). These participants with long term exposure were also taking oestrogens more often (55.5\% $(46701 / 84113) \quad v \quad 31.9 \% \quad(12709 / 39884))$. The incidence of meningioma in the exposed population was 141 per 100000 person years (447 participants), an excess risk of more than 20-fold (adjusted hazard ratio 21.2 , 95\% confidence interval 12.8 to 35.1 ). A strong dose-effect relation was also observed, with adjusted hazard ratio ranging from 5.0 (2.0 to 12.5$)$ to 31.1 (18.4 to 52.0). Beyond a cumulative dose of $60 \mathrm{~g}$ after 2006, the incidence was 383 per 100000 person years (supplementary material S14).

In the analysis of the cohort of transgender participants, the incidence of meningioma in the exposed population was 20.7 per 100000 person years (three participants) versus 0 in the control group of transgender women $(\mathrm{P}=0.08)$. The three people with meningioma in the exposed group who required surgery were those taking very high daily doses of 100-150 mg for relatively short exposure periods of 3-4.5 years.

\section{Meningioma in participants who used cyproterone acetate}

Of the 516 cyproterone acetate users ( 69 from the main cohort and 447 from the complementary cohort of girls and women who were already using cyproterone acetate in 2006) admitted to hospital and treated aggressively for meningioma, $96.0 \%$ underwent a neurosurgical procedure and $4.0 \%$ were treated by radiotherapy (table 4). Participants younger than 35 years accounted for only $6.6 \%$ of all those with meningioma, whereas most participants were older than 45 years $(60.5 \%)$. The mean length of the initial hospital stay was 10 days. The locations of meningiomas that required surgery in these exposed participants were noticeably different from those observed in control group participants (table 4). The two most common anatomical locations of meningioma among cyproterone acetate users were anterior skull base $(\mathrm{n}=190)$ and middle skull base ( $n=130$; table 4). The absolute and relative risks of meningioma differed considerably according to the anatomical locations of meningiomas (supplementary material S15). In particular, meningiomas of the anterior skull base with a 47 -fold increased risk (95\% confidence interval 14.9 to 149.1 ) occurred in those with prolonged use of cyproterone acetate.

In $29.5 \%$ of patients, antiepileptic drug treatment was continued for one to two years after discharge from hospital. All cause 30 day and one year mortality after the initial hospital stay were $1.2 \%(6 / 516)$ and $1.6 \%$ (8/516), respectively.

In the 516 participants with treated meningioma among cyproterone acetate users, 152 (29.5\%) resumed cyproterone acetate during the first year after neurosurgery or radiotherapy. Resumption of cyproterone acetate after neurosurgery or radiotherapy decreased significantly over time (47\% (10/21) resumption rate in $2007 v 15 \%$ (9/60) in 2014 and $19 \%(11 / 58)$ in 2015). The cyproterone acetate resumption rate was therefore $37 \%$ (97/263) during the period before modification of the labelling (200711) compared with $22 \%(56 / 253)$ after modification of the labelling for the brand name drug (2012-15).

The estimated number of people with meningioma attributable to cyproterone acetate was more than 500 in France for the period 2007-15 (62 per year; supplementary material S16). This estimate is based on a conservative calculation that does not take into account those with a diagnosis more than one year after discontinuation of cyproterone acetate, those with a diagnosis after an initial classification of very slightly exposed (control group) and subsequent resumption of cyproterone acetate, and meningiomas managed by medical follow-up without surgery or radiotherapy.

\section{Discussion}

This study shows a strong, dose dependent association between use of cyproterone acetate and risk of meningioma requiring invasive treatment. The risk of meningioma appeared to be greatest in girls and women already treated by cyproterone acetate in 2006, with a cumulative dose of more than $60 \mathrm{~g}$ between 2007 and 2015, with four participants with meningioma per 1000 person years. The risk of meningioma decreased noticeably after treatment was stopped for one year.

Meningiomas occurring in association with use of cyproterone acetate were located in particular sites, with an almost 47-fold excess risk of anterior skull base meningioma. Most of the participants with meningioma had taken cyproterone acetate for off label indications, and around 30\% had even continued

\begin{tabular}{|c|c|c|c|c|c|}
\hline Drug use & Person years & $\begin{array}{l}\text { No of } \\
\text { meningiomas }\end{array}$ & $\begin{array}{l}\text { Incidence per } \\
100000 \text { person years }\end{array}$ & $\begin{array}{l}\text { Relative risk } \\
(95 \% \mathrm{Cl})\end{array}$ & $\begin{array}{l}\text { Adjusted hazard ratio } \\
(95 \% \mathrm{Cl})^{\star}\end{array}$ \\
\hline Control group ( $<3 \mathrm{~g})$ & 439949 & 20 & 4.5 & Reference & Reference \\
\hline Exposed ( $\geq 3 \mathrm{~g}$ ) & 289544 & 69 & 23.8 & $5.2(3.2$ to 8.6$)$ & $6.6(4.0$ to 11.1$)$ \\
\hline \multicolumn{6}{|l|}{ Cumulative dose (g): } \\
\hline$\geq 6$ to $<12$ & 79202 & 6 & 7.6 & $1.7(0.7$ to 4.1$)$ & $2.2(0.9$ to 5.6$)$ \\
\hline$\geq 12$ to $<36$ & 115594 & 30 & 26.0 & 5.7 (3.2 to 10.1$)$ & 6.4 (3.6 to 11.5$)$ \\
\hline$\geq 36$ to $<60$ & 29390 & 16 & 54.4 & $12.0(6.2$ to 23.1$)$ & 11.3 (5.8 to 22.2 ) \\
\hline$\geq 60$ & 11615 & 15 & 129.1 & $28.4(14.5$ to 55.5$)$ & 21.7 (10.8 to 43.5) \\
\hline
\end{tabular}




\begin{tabular}{|c|c|c|c|}
\hline Variables & Exposed $(n=516)$ & Control group $(n=36)$ & $P$ value \\
\hline \multicolumn{4}{|l|}{ Initial treatment } \\
\hline Neurosurgery & $495(95.9)$ & $32(88.9)$ & - \\
\hline Radiotherapy & $21(4.1)$ & $4(11.1)$ & 0.07 \\
\hline \multicolumn{4}{|l|}{ Age at diagnosis (years) } \\
\hline Mean (SD) & $48.1(9.5)$ & $50.5(13.1)$ & 0.30 \\
\hline Median (interquartile range): & $47.1(42.1-53.6)$ & $50.4(40.2-58.6)$ & - \\
\hline $7-24$ & $1(0.2)$ & $0(0.0)$ & - \\
\hline $25-34$ & $33(6.4)$ & $4(11.1)$ & - \\
\hline $35-44$ & $170(32.9)$ & $9(25.0)$ & - \\
\hline $45-54$ & $204(39.5)$ & $11(30.6)$ & - \\
\hline $55-64$ & $78(15.1)$ & $6(16.7)$ & - \\
\hline$\geq 65$ & $30(5.8)$ & $6(16.7)$ & 0.11 \\
\hline \multicolumn{4}{|l|}{ Cumulative dose (g) } \\
\hline$<3$ & $0(0.0)$ & $36(100.0)$ & - \\
\hline$\geq 3$ to $<6$ & $2(0.4)$ & $0(0.0)$ & - \\
\hline$\geq 6$ to $<12$ & $14(2.7)$ & $0(0.0)$ & - \\
\hline$\geq 12$ to $<36$ & $149(28.9)$ & $0(0.0)$ & - \\
\hline$\geq 36$ to $<60$ & $141(27.3)$ & $0(0.0)$ & - \\
\hline$\geq 60$ & $210(40.7)$ & $0(0.0)$ & $<0.001$ \\
\hline \multicolumn{4}{|l|}{ Anatomical location of meningioma (six groups)* } \\
\hline Group 1: anterior skull base & $190(36.8)$ & $7(19.4)$ & - \\
\hline Group 2: middle skull base & $130(25.2)$ & $9(25.0)$ & - \\
\hline Group 3: posterior skull base & $20(3.9)$ & $3(8.3)$ & - \\
\hline Group 4: convexity, not involving dural venous sinuses & $107(20.7)$ & $4(11.1)$ & - \\
\hline Group 5: convexity, involving dural venous sinuses & $19(3.7)$ & $2(5.6)$ & - \\
\hline Group 6: falx and tentorium & $29(5.6)$ & $7(19.4)$ & - \\
\hline Missing (no surgery) & $21(4.1)$ & $4(11.1)$ & 0.003 \\
\hline \multicolumn{4}{|l|}{ Anatomical location of meningioma (16 groups)* } \\
\hline Anterior skull base & $120(23.3)$ & $3(8.3)$ & - \\
\hline Optic chiasma or hypothalamic region & $70(13.6)$ & $4(11.1)$ & - \\
\hline Middle skull base & $47(9.1)$ & $3(8.3)$ & - \\
\hline Medial third of middle skull base: spheno-orbital region & $81(15.7)$ & $4(11.1)$ & - \\
\hline Sella turcica & $2(0.4)$ & $2(5.6)$ & - \\
\hline Cerebellopontine angle or internal auditory meatus & $6(1.2)$ & $2(5.6)$ & - \\
\hline Cerebelli convexity, invading a dural venous sinus & $6(1.2)$ & $0(0.0)$ & - \\
\hline Clivus & $4(0.8)$ & $0(0.0)$ & - \\
\hline Jugular foramen & $2(0.4)$ & $0(0.0)$ & - \\
\hline Foramen magnum & $2(0.4)$ & $0(0.0)$ & - \\
\hline Petroclival region & $0(0.0)$ & $1(2.8)$ & - \\
\hline Brain convexity, not involving dural venous sinuses & $107(20.7)$ & $4(11.1)$ & - \\
\hline Brain convexity, invading a dural venous sinus & $19(3.7)$ & $2(5.6)$ & - \\
\hline Falx cerebri & $19(3.7)$ & $5(13.9)$ & - \\
\hline Tentorium cerebelli & $4(0.8)$ & $0(0.0)$ & - \\
\hline Tentorial incisure & $6(1.2)$ & $2(5.6)$ & NC \\
\hline Missing (no surgery) & $21(4.1)$ & $4(11.1)$ & - \\
\hline \multicolumn{4}{|l|}{ Magnetic resonance imaging } \\
\hline 6 to 18 months before event & $52(10.1)$ & $8(22.2)$ & 0.05 \\
\hline 1 year after event & 477 (96.3) & $31(86.1)$ & 0.19 \\
\hline \multicolumn{4}{|l|}{ Duration of hospital stay for initial treatment (days) } \\
\hline Mean (SD) & $10.3(8.1)$ & $9.1(6.6)$ & 0.36 \\
\hline Median (interquartile range): & $8(7-12)$ & $7(6-10)$ & - \\
\hline$<7$ days & $128(24.8)$ & $11(30.6)$ & - \\
\hline 7-9 days & $193(37.4)$ & $15(41.7)$ & - \\
\hline$\geq 10$ days & $195(37.8)$ & $10(27.8)$ & 0.45 \\
\hline \multicolumn{4}{|l|}{ Death } \\
\hline $0-30$ days & $6(1.2)$ & $0(0.0)$ & 1 \\
\hline 0 days to 1 year & $8(1.6)$ & $0(0.0)$ & 1 \\
\hline \multicolumn{4}{|l|}{ Antiepileptic drug treatment } \\
\hline Date of discharge to 1 year & $297(57.6)$ & $26(72.2)$ & 0.11 \\
\hline 1-2 years after discharge from hospital & $152(29.5)$ & $13(36.1)$ & 0.45 \\
\hline \multicolumn{4}{|l|}{ Admission to hospital for seizures } \\
\hline Date of discharge to 1 year & $9(1.7)$ & $0(0.0)$ & 1 \\
\hline 1-2 years after initial discharge from hospital & $9(1.7)$ & $0(0.0)$ & 1 \\
\hline \multicolumn{4}{|l|}{ Neurosurgery reoperation } \\
\hline Date of discharge to 1 year & $11(2.1)$ & $2(5.6)$ & 0.21 \\
\hline $1-2$ years after initial operation & $10(1.9)$ & $0(0.0)$ & 1 \\
\hline
\end{tabular}


or resumed cyproterone acetate after treatment of the meningioma, which has been formally contraindicated since 2011.

\section{Comparison with published data \\ Risk and causality}

Two epidemiological studies have assessed the link between cyproterone acetate use and meningioma. The first study, by Gil and colleagues, ${ }^{14}$ included a retrospective Spanish cohort and identified two men and two women with meningioma in the group using high dose cyproterone acetate. The absolute risk was 60 per 100000 person years and the relative risk (regardless of sex) was 11.4 (95\% confidence interval 4.3 to 30.8), corresponding to an intermediate risk between those observed in our cohort and women already exposed in 2006. Because of its low power, this study did not allow any subgroup analysis, description and adjustment for other risk factors, or a study of the dose-effect relation. However, the findings confirmed, as early as 2011, an already reported indication and provided an important contribution to the identification of a probable causal relation. The second study, by Cea-Soriano and colleagues, ${ }^{15}$ was a case-control study of a cohort in the United Kingdom. This study was more generally designed to examine the link between hormonal treatment and meningioma. An excess risk associated with cyproterone acetate was found in men (four men with meningioma), with an odds ratio of 3.3 (95\% confidence interval 1.0 to 10.6). However, no association was observed for women, probably because women received a relatively low daily dose of $2 \mathrm{mg}$ cyproterone acetate in combination with an oestrogen.

These two studies ${ }^{14}{ }^{15}$ and our own study are complementary and provide a coherent set of epidemiological evidence. They show a documented risk for high dose cyproterone acetate in men, women, and transgender people, and the absence of any observed risk for low dose cyproterone acetate use in women.

The two main identified risk factors for meningioma, apart from age and female sex, are genetic predispositions, especially attributed to hereditary mutations of the neurofibromatosis type 2 gene, ${ }^{27-31}$ and environmental or medical exposure to high dose ionising radiation ${ }^{32-42}$; however, these risk factors account for only 1-2\% of all meningiomas. Arguments in support of an association between sex hormones and meningiomas include the increased incidence of meningioma after puberty in women compared with men $(2: 1)$, with the highest ratio (3.15:1) observed in women of childbearing age; observations that meningiomas increase in size during the luteal phase of the menstrual cycle and during pregnancy, or regress after delivery; the presence of oestrogen, progesterone, and androgen receptors in certain meningiomas ${ }^{43-50}$; and a moderately increased association between breast cancer and meningiomas. ${ }^{5152}$

Numerous studies have also investigated whether the use of exogenous sex hormones, such as oral contraceptives or hormone replacement therapy, is associated with an increased risk of meningioma. At present no evidence exists of an excess risk of meningioma in women who use oral contraceptives. No association has been established between past or present use of oral contraceptives and the risk of meningioma. ${ }^{45} 4753$ More consistent associations have been shown with hormone replacement therapy, although the increased risk seems to remain limited. The meta-analysis by Benson and colleagues ${ }^{54}$ reported an increased risk of meningioma with hormone replacement therapy, with a relative risk of 1.35 (95\% confidence interval 1.21 to 1.49 ). The main published studies have reported excess risks of meningioma ranging between 1.2 and 2.2. These studies appear to show that the use of progestogen is an independent risk factor for the development and growth of meningiomas. However, the magnitude of the risk observed with hormone replacement therapy is much lower than that observed with high dose cyproterone acetate in our study. Wiemels and colleagues ${ }^{27}$ called for larger scale studies on the use of exogenous hormones in women with meningioma, with particular attention paid to stratification according to hormone composition (oestrogen or progesterone), duration and age of use, and subgroups of meningiomas defined by tumour receptor expression.

Additionally, the presence of progesterone receptors in arachnoid tissue, from which meningiomas arise, has been known for four decades. ${ }^{55-59}$ Several authors have reported a heterogeneous distribution of progesterone receptors according to the site of meningiomas. A rostrocaudal gradient of progesterone receptors, with a higher density of receptors in the skull base, has often been reported, and was confirmed by several publications. ${ }^{6061}$ Our finding of a predominance of anterior skull base meningiomas related to use of cyproterone acetate, a progestogen, is consistent with these biological findings.

Peyre and colleagues ${ }^{62}$ recently compared 40 patients who had surgery for meningioma after prolonged treatment with progestogens with 530 women with meningiomas arising in the absence of hormone therapy. Progestogen related meningiomas were more commonly multiple meningiomas situated in the skull base (a predominant location also observed in our study). These authors showed a higher incidence of PIK3CA (mutations also found in endometrial carcinoma, breast cancer, and cervical carcinoma) and TRAF7 (tumour necrosis factor receptor associated factor 7) mutations, and a lower incidence of NF2 (neurofibromatosis type 2) mutations in progestogen related meningiomas compared with non-progestogen related meningiomas, suggesting a hormone induced mutational shift. ${ }^{62}$

Biologically, an association between use of high dose cyproterone acetate and the development of meningioma is highly plausible. This explanation in favour of a causal relation provides further support to the other four explanations provided by our study: the strength of the association, the dose-effect relation, 
the reduction in risk after stopping treatment, and the specificity of certain tumour locations, especially the anterior skull base. The use of cyproterone acetate determines a new form of meningiomatosis, which corresponds to hormone sensitive meningiomas.

\section{Use of high dose cyproterone acetate in women}

Our study reports extensive off label use of cyproterone acetate, similar to the study by Bernat and colleagues, ${ }^{7}$ which included 12 women, only one of whom was treated for hirsutism, with one or more meningiomas after treatment with high dose cyproterone acetate. The other reported indications for cyproterone acetate $^{7} \quad{ }^{63} 64$ were acne, hyperandrogenism, contraception, dysmenorrhoea, polycystic ovary syndrome, alopecia, and menopause. Most of the clinical cases reported in the international scientific literature were concentrated in four countries (France, Spain, Italy, and Belgium), reflecting different indications and uses compared with those observed in Asian and Anglo-Saxon countries, where the use of high dose cyproterone acetate for dermatological and gynaecological indications such as contraception is not approved. High dose cyproterone acetate is not currently marketed in the United States, where other antiandrogens are used.

France accounts for about $60 \%$ of all sales of $50 \mathrm{mg}$ cyproterone acetate ${ }^{65}$ (used by women and men) among European countries with similar populations (Germany, Spain, UK, and Italy). In some European countries (Belgium, Cyprus, Germany, Greece, Luxembourg, the Netherlands, and Portugal) cyproterone acetate is marketed at a lower dose strength of $10 \mathrm{mg}$, with or without the $50 \mathrm{mg}$ dose (table 1), which has probably limited the risk of cyproterone acetate related meningioma in these countries. Cyproterone acetate, marketed under various trade names, is extensively used in Latin American countries, especially Argentina and Brazil.

\section{Clinical management of cyproterone acetate related meningiomas}

A large proportion of meningiomas involve the skull base, which is of considerable importance because skull base meningioma surgery is one of the most challenging forms of surgery and is associated with a much higher risk than surgery for convexity meningiomas. Several case series of cyproterone acetate related meningiomas have reported regression or stabilisation of meningiomas after discontinuation of cyproterone acetate, suggesting that surgery could be avoided in these patients. ${ }^{2-46-8} 1166$ The results of our study showed a noticeable reduction in risk of invasive treatment for meningioma after one year of discontinuation of cyproterone acetate. These findings are consistent with the results of previous studies comprising follow-up using magnetic resonance imaging. Discontinuation of cyproterone acetate in the presence of meningioma should be considered a valid treatment option before surgery, provided close clinical and magnetic resonance imaging surveillance is ensured, with comparative measurement of tumour volumes. $^{781166}$

Despite the benign histology of meningiomas, surgical complications are not uncommon: antiepileptic drug treatment was continued for more than one year after surgery in more than $30 \%$ of patients in our study. Van der Vossen and colleagues ${ }^{67}$ showed that $40 \%$ of patients who had surgery for meningioma experienced cognitive or emotional disorders for an average of 2.5 years after surgery.

\section{Strengths of this study}

The large cohort (1300000 person years exposed) studied provides new information about the dose-effect relation, the anatomical locations of meningiomas requiring surgery, the effect of discontinuation of treatment, and the attributable number of cases. This study was based on SNDS, a national database and was conducted on a large unselected population, in whom use of cyproterone acetate was measured prospectively over time by pharmacists dispensing drugs, recorded by bar code for the purposes of financial monitoring, and independent of the event of interest. There was no recall bias, unlike older studies that were generally based on retrospective drug use data derived from meningioma registries.

Another strength of this study is that we used an event of interest linking a diagnosis (meningioma) with interventional management (neurosurgery, in $96 \%$ of cases, or radiotherapy). This definition of the event ensures a high specificity and consequently minimises the effect of misclassification error on risk estimation. This is particularly important because a small asymptomatic meningioma (not causing neurological deficits) might be discovered incidentally on imaging, which could induce differential errors when imaging is performed more often in closely monitored people using cyproterone acetate. The requirement of an associated therapeutic procedure ${ }^{68}$ restricts the study to tumours with present or imminent neurological consequences, less subject to a discovery bias, and also confirmed by histological examination, making the event highly specific when defined in this way. Such a definition of cases, used in the context of a pharmacoepidemiological approach, also avoided the limitations of a pharmacovigilance approach based on heterogeneous spontaneous reporting by healthcare professionals. Only a pharmacoepidemiological approach can provide estimates of absolute risk, relative risk, and attributable number of cases of an adverse event. ${ }^{69}$

\section{Limitations of this study}

Like all real life observational studies, this study has several limitations. The indications for high dose cyproterone acetate were poorly defined, although this does not affect the level of risk because no association was observed in our study between the context of prescription (hirsutism, acne) and the risk of meningioma. However, the poorly defined indications constitute a serious limitation in terms of determination 
of the benefit-risk balance of the drug, which is essential in view of the extensive off label use of cyproterone acetate in France. The Meningioma and Cyproterone Acetate Temporary Specialised Scientific Committee, formed by the French Medicines Agency, formulated its conclusions at a meeting on 1 October 2018, when it considered that the use of cyproterone acetate for off label indications such as acne, seborrhoea, and moderate hirsutism should be formally banned. ${ }^{70}$ In light of this report, in February 2020 the European Medicines Agency recommended that drugs containing $10 \mathrm{mg}$ or more of cyproterone acetate should only be used for hirsutism, androgenic alopecia, and acne and seborrhoea once other treatment options have failed, including treatment with lower doses. ${ }^{71}$

Another limitation of this study was the failure to take into account the combined oral contraceptive pill containing $2 \mathrm{mg}$ of cyproterone acetate, which is not reimbursed and therefore not present in SNDS. However, the $50 \mathrm{mg} /$ day dosage studied here is 25 -fold higher than $2 \mathrm{mg}$, therefore this low dose would have only had a marginal impact on the cumulative dose calculation of cyproterone acetate. Additionally, as is often the case in pharmacoepidemiology, even with regular dispensing of a drug such as cyproterone acetate by a pharmacist with a prescription from a doctor, reimbursement of this drug by national health insurance cannot be strictly equated with drug use. Patients might not always take the drugs dispensed by pharmacists.

According to several published case series, most meningiomas occur after use of cyproterone acetate for 10-30 years. However, at the time of this study, SNDS comprised only 10 years of follow-up. Therefore, we created a cohort of participants who started cyproterone acetate between 2007 and 2014 for the main analysis, and considered girls and women already taking cyproterone acetate in 2006, who started treatment at an unknown date, only in the complementary analyses. This approach makes presentation of the results of the study slightly more complicated, but enhances the validity of the conclusions.

Several limitations also concern the clinical and histological characteristics of meningioma. SNDS does not contain data on the results of magnetic resonance imaging or histology, or whether meningiomas are single or multiple, except for operations that involve distinct anatomical regions.

Finally, the identification of the meningiomas are not specified in detail, but the neurosurgical management, most probably according to current European guidelines, ${ }^{68}$ reflects the symptomatic nature of the tumour related to its volume or location. Fewer than $10 \%$ of treated patients had undergone magnetic resonance imaging between six and 18 months before surgery. The results (number and size of meningiomas) are not available, but reimbursement of the procedure can be identified in the database. Therefore, this study probably underestimates the overall incidence of intracranial meningiomas because most of these tumours, small or asymptomatic tumours, are simply followed by magnetic resonance imaging. We consider that a reverse causality bias, always possible if the prescription of cyproterone acetate was linked to an as yet undiagnosed meningioma, can be excluded in this study because the risk of meningioma increased with the duration of cyproterone acetate use and cumulative doses, and not during the initial phase of drug use. Nevertheless, the endpoint used in this study (neurosurgical resection or radiotherapy) corresponds to a pragmatic and clinically significant event. Meningioma incidence rates in girls and women with low use of cyproterone acetate in our study were similar to those reported in the reference epidemiological publications $^{27}$ (supplementary material S17).

The risk of meningioma associated with other potent, high dose progestogens, such as nomegestrol acetate $^{7273}$ and chlormadinone acetate, should also be evaluated by using similar methods. ${ }^{74}$ Currently, no evidence exists to suggest a similar magnitude of risk to that associated with cyproterone acetate.

\section{Clinical implications of this study}

People who use high dose cyproterone acetate for at least three to five years should be informed about the increased risk of intracranial meningioma. The indication of cyproterone acetate should be clearly defined and the lowest possible daily dose used. In the context of prolonged use of high dose cyproterone acetate, magnetic resonance imaging screening for meningioma should be considered. In patients with a documented meningioma, cyproterone acetate should be discontinued because the meningioma might regress in response to treatment discontinuation and invasive treatment could be avoided.

\section{Conclusion}

More than 400000 girls and women in France used high dose cyproterone acetate between 2006 and 2015, predominantly for off label indications. A strong and dose dependent association between use of cyproterone acetate and meningioma treated by surgery or radiotherapy was observed in these people. Based on available follow-up, the risk of meningioma decreased noticeably after treatment was stopped. In light of these results, prescription of cyproterone acetate, especially for off label indications, should be considered carefully, with more detailed assessment of the risk-benefit balance for approved indications. Additionally, more thorough screening and monitoring of meningioma by brain magnetic resonance imaging should be performed when prescription of cyproterone acetate seems to be necessary.

We thank Anthony Saul for English revision of the manuscript, Emilie Sbidian (dermatologist) for his expertise, Olivier Lyon-Caen (neurologist), Henry Dufour (neurosurgeon), Rosemary Dray-Spira (epidemiologist), Mahmoud Zureik (epidemiologist), Etienne Richer (obstetrician gynaecologist), Moussa Laanani (epidemiologist), Léa Hoisnard (public health resident), and Anke Neumann (statistician) for providing their comments and suggestions.

Contributors: SFo, SFr, AW, and JC had the idea for the study. AW and $J C$ conceived and planned the study. AW drafted the manuscript. $\mathrm{BC}$ performed data management. BC and PN performed statistical analyses. AW and JC ensured project and study management. All authors (AW, PN, ML, BC, TP, LD, ALB, IY, SFo, SFr, and JC) contributed 
to interpretation of the data and revised the manuscript. All authors approved the final manuscript. The corresponding author (AW) attests that all listed authors meet authorship criteria and that no others meeting the criteria have been omitted. AW and JC are the guarantors. Funding: This research was funded by the French National Health Insurance Fund (CNAM) and the Health Product Epidemiology Scientific Interest Group (ANSM-CNAM EPI-PHARE SIG). AW, JC, and $\mathrm{BC}$ are employees of French National Health Insurance Fund, $\mathrm{PN}$ is an employee of the French National Agency for Medicines and Health Products Safety. The present paper represents the opinions of the authors and does not necessarily reflect the position of their employers.

Competing interests: All authors have completed the ICMJE uniform disclosure form at www.icmje.org/coi_disclosure.pdf and declare: support from French National Health Insurance Fund (CNAM) and the Health Product Epidemiology Scientific Interest Group (ANSM-CNAM EPI-PHARE SIG) for the submitted work; no financial relationships with any organisations that might have an interest in the submitted work in the previous three years; no other relationships or activities that could appear to have influenced the submitted work.

Ethical approval: This research was authorised by the French Data Protection Agency (CNIL).

Data sharing: No additional data available by author (French law to access SNDS https://www.snds.gouv.fr).

The lead author (AW) affirms that this manuscript is an honest, accurate and transparent account of the study being reported; that no important aspects of the study have been omitted; and that any discrepancies from the study as planned (and, if relevant, registered) have been explained.

Dissemination to participants and related patient and public communities: The results were presented to patient association representatives. Patients who had used cyproterone acetate 50/100 $\mathrm{mg}$ over the previous two years (and their general practitioners) received an information letter at home providing detailed information on what to do (supplementary material S18).

Provenance and peer review: Not commissioned; externally peer reviewed.

This is an Open Access article distributed in accordance with the terms of the Creative Commons Attribution (CC BY 4.0) license, which permits others to distribute, remix, adapt and build upon this work, for commercial use, provided the original work is properly cited. See: http://creativecommons.org/licenses/by/4.0/.

1 Gazzeri R, Galarza M, Gazzeri G. Growth of a meningioma in a transsexual patient after estrogen-progestin therapy. N Engl J Med 2007;357:2411-2. doi:10.1056/NEJMc071938.

2 Froelich S, Dali-Youcef N, Boyer P, et al. Does cyproterone acetate promote multiple meningiomas? Endocr Abstr Proc 10th Eur Congr Endocrinol Berl Ger 2008;16:158.

3 Gonçalves AMG, Page P, Domigo V, Méder JF, Oppenheim C. Abrupt regression of a meningioma after discontinuation of cyproterone treatment. AINR Am / Neuroradiol 2010;31:1504-5. doi:10.3174/ ajnr.A1978.

4 Cebula H, Pham TQ, Boyer P, Froelich S. Regression of meningiomas after discontinuation of cyproterone acetate in a transsexual patient. Acta Neurochir (Wien) 2010;152:1955-6. doi:10.1007/s00701 010-0787-2.

5 Bergoglio MT, Gómez-Balaguer M, Almonacid Folch E, Hurtado Murillo F, Hernández-Mijares A. Symptomatic meningioma induced by cross-sex hormone treatment in a male-to-female transsexual. Endocrinol Nutr 2013;60:264-7. doi:10.1016/j. endonu 2012.07.004

6 Sys C, Kestelyn P. Unilateral proptosis and blindness caused by meningioma in a patient treated with cyproterone acetate. GMS Ophthalmol Cases 2015:5:Doc05. doi:10.3205/oc000027.

7 Bernat AL, Oyama K, Hamdi S, et al. Growth stabilization and regression of meningiomas after discontinuation of cyproterone acetate: a case series of 12 patients. Acta Neurochir Wien) 2015:157:1741-6 doi:10.1007/s00701-015-2532-3.

8 Botella C, Coll G, Lemaire J-J, Irthum B. Méningiomes intracrâniens et utilisation prolongée d'acétate de cyprotérone à dose conventionnelle chez la femme: à propos de deux cas de régression tumorale après arrêt du traitement. Neurochirurgie 2015;61:339-42. doi:10.1016/j.neuchi.2015.05.002

9 Alderman CP. Probable Drug-Related Meningioma Detected During the Course of Medication Review Services. Consult Pharm 2016;31:500-4. doi:10.4140/TCP.n.2016.500

10 Borghei-Razavi H, Fragoza-Padilla V, Hargus G, et al. Meningioma: The Unusual Growth in a Transsexual Patient after Estrogen-Progesterone Therapy. SOJ Neurol 2014;1:1-3.
11 Zairi F, Aboukais R, LE Rhun E, Marinho P, Maurage CA, Lejeune JP. Close follow-up after discontinuation of cyproterone acetate: a possible option to defer surgery in patients with voluminous intracranial meningioma. J Neurosurg Sci 2017;61:98-101. doi:10.23736/S0390-5616.16.03243-4.

12 HMA. PhVWP Report on Cyproterone acetate and the risk of meningiomas Provided to the CMD(h) on behalf of National Competent Authories. Changes apply to cyproterone-containing drugs with dosages higher than 2mg. 2009. www.hma.eu/fileadmin/dateien/Human Medicines/CMD_h_/Product_Information/PhVWP_Recommendations/ Cyproterone/CMDh-PhVWP-012-Rev0_2009_11.pdf

13 ANSM. Résumé des Caractéristiques du Produit; ANSM - Mis à jour le: 20/11/2012; ANDROCUR 50 mg, comprimé sécable. 2012. http:// agence-prd.ansm.sante.fr/php/ecodex/rcp/R0221731.htm

14 Gil M, Oliva B, Timoner J, Maciá MA, Bryant V, de Abajo FJ. Risk of meningioma among users of high doses of cyproterone acetate as compared with the general population: evidence from a population-based cohort study. Br J Clin Pharmacol 2011;72:965-8. doi:10.1111/j.1365-2125.2011.04031.x.

15 Cea-Soriano L, Blenk T, Wallander M-A, Rodríguez LA Hormonal therapies and meningioma: is there a link? Cancer Epidemiol 2012;36:198-205. doi:10.1016/j.canep.2011.08.003.

16 Tuppin P, Rudant J, Constantinou P, et al. Value of a national administrative database to guide public decisions: From the système national d'information interrégimes de l'Assurance Maladie (SNIIRAM) to the système national des données de santé (SNDS) in France. Rev Epidemiol Sante Publique 2017;65(Suppl 4):S149-67. doi:10.1016/j.respe.2017.05.004.

17 Bezin J, Duong M, Lassalle R, et al. The national healthcare system claims databases in France, SNIIRAM and EGB: Powerful tools for pharmacoepidemiology. Pharmacoepidemiol Drug Saf 2017;26:95462. doi:10.1002/pds.4233

18 Moulis G, Lapeyre-Mestre M, Palmaro A, Pugnet G, Montastruc IL, Sailler L. French health insurance databases: what interest for medical research?Rev Med Interne 2015;36:411-7. doi:10.1016/j. revmed.2014.11.009.

19 Maura G, Blotière P-O, Bouillon K, et al. Comparison of the short-term risk of bleeding and arterial thromboembolic events in nonvalvular atrial fibrillation patients newly treated with dabigatran or rivaroxaban versus vitamin K antagonists: a French nationwide propensity-matched cohort study. Circulation 2015;132:1252-60. doi:10.1161/CIRCULATIONAHA.115.015710.

20 Weill A, Dalichampt M, Raguideau F, et al. Low dose oestrogen combined oral contraception and risk of pulmonary embolism, stroke, and myocardial infarction in five million French women: cohort study. BM/ 2016;353:i2002. doi:10.1136/bmj.i2002.

21 Basson M, Mezzarobba M, Weill A, et al. Severe intestinal malabsorption associated with olmesartan: a French nationwide observational cohort study. Gut 2016;65:1664-9. doi:10.1136/ gutjint-2015-309690.

22 Lemaitre M, Kirchgesner J, Rudnichi A, et al. Association between use of thiopurines or tumor necrosis factor antagonists alone or in combination and risk of lymphoma in patients with inflammatory bowel disease. JAMA 2017;318:1679-86. doi:10.1001/jama.2017.16071.

23 Blotière P-O, Raguideau F, Weill A, et al. Risks of 23 specific malformations associated with prenatal exposure to 10 antiepileptic drugs. Neurology 2019;93:e167-80. doi:10.1212/ WNL.0000000000007696.

24 Meyer A, Rudant J, Drouin J, Weill A, Carbonnel F, Coste J. Effectiveness and safety of reference infliximab and biosimilar in Crohn disease: a french equivalence study. Ann Intern Med 2019;170:99-107. doi:10.7326/M18-1512

25 Giral P, Neumann A, Weill A, Coste J. Cardiovascular effect of discontinuing statins for primary prevention at the age of 75 years: a nationwide population-based cohort study in France. Eur Heart) 2019:40:3516-25. doi:10.1093/eurheartj/ehz458.

26 Grave C, Boucheron P, Rudant J, et al. Seasonal influenza vaccine and Guillain-Barré syndrome: A self-controlled case series study. Neurology 2020;94:e2168-79. doi:10.1212/WNL.0000000000009180.

27 Wiemels J, Wrensch M, Claus EB. Epidemiology and etiology of meningioma. J Neurooncol 2010;99:307-14. doi:10.1007/s11060 010-0386-3.

28 Malmer B, Henriksson R, Grönberg H. Familial brain tumoursgenetics or environment? A nationwide cohort study of cancer risk in spouses and first-degree relatives of brain tumour patients. Int Cancer 2003;106:260-3. doi:10.1002/ijc.11213.

29 Hemminki K, Tretli S, Sundquist J, Johannesen TB, Granström C. Familial risks in nervous-system tumours: a histology-specific analysis from Sweden and Norway. Lancet Oncol 2009;10:481-8. doi:10.1016/S1470-2045(09)70076-2.

30 Hansson CM, Buckley PG, Grigelioniene G, et al. Comprehensive genetic and epigenetic analysis of sporadic meningioma for macromutations on $22 \mathrm{q}$ and micro-mutations within the NF2 locus. BMC Genomics 2007;8:16. doi:10.1186/1471-2164-8-16. 
31 Champeaux-Depond C, Weller J, Resche-Rigon M. Neurofibromatosis type 2: a nationwide population-based study focused on survival after meningioma surgery. Clin Neurol Neurosurg 2020;198:106236. doi:10.1016/j.clineuro.2020.106236.

32 Hijiya N, Hudson MM, Lensing S, et al. Cumulative incidence of secondary neoplasms as a first event after childhood acute lymphoblastic leukemia. JAMA 2007;297:1207-15. doi:10.1001/ jama.297.11.1207.

33 Preston DL, Ron E, Yonehara S, et al. Tumors of the nervous system and pituitary gland associated with atomic bomb radiation exposure. J Natl Cancer Inst 2002;94:1555-63. doi:10.1093/jnci/94.20.1555

34 Ron E, Modan B, Boice JDJr, et al. Tumors of the brain and nervous system after radiotherapy in childhood. $N$ Engl $)$ Med 1988;319:1033-9. doi:10.1056/NEJM198810203191601.

35 Sadetzki S, Flint-Richter P, Ben-Tal T, Nass D. Radiationinduced meningioma: a descriptive study of 253 cases. J Neurosurg 2002;97:1078-82. doi:10.3171/jns.2002.97.5.1078

36 Sadetzki S, Flint-Richter P, Starinsky S, et al. Genotyping of patients with sporadic and radiation-associated meningiomas. Cancer Epidemiol Biomarkers Prev 2005;14:969-76. doi:10.1158/1055 9965.EPI-04-0366.

37 Preston-Martin S. Descriptive epidemiology of primary tumors of the spinal cord and spinal meninges in Los Angeles County, 1972-1985. Neuroepidemiology 1990;9:106-11. doi:10.1159/000110757.

38 Ryan P, Lee MW, North B, McMichael AJ. Amalgam fillings, diagnostic dental $x$-rays and tumours of the brain and meninges. Eur I Cancer $B$ Oral Oncol 1992;28B:91-5. doi:10.1016/0964-1955(92)90034-X

39 Swerdlow AJ, Cooke R, Beckers D, et al. Risk of meningioma in European patients treated with growth hormone in childhood: results from the SAGhE cohort. J Clin Endocrinol Metab 2019;104:658-64. doi:10.1210/jc.2018-01133.

40 Braganza MZ, Kitahara CM, Berrington de González A, Inskip PD, Johnson KJ, Rajaraman P. Ionizing radiation and the risk of brain and central nervous system tumors: a systematic review. Neuro Oncol 2012;14:1316-24. doi:10.1093/neuonc/nos208.

41 Taylor Al, Little MP. Winter DL, et al. Population-based risks of CNS tumors in survivors of childhood cancer: the British Childhood Cancer Survivor Study. J Clin Oncol 2010;28:5287-93. doi:10.1200/ ICO.2009.27.0090.

42 Neglia JP, Robison LL, Stovall M, et al. New primary neoplasms of the central nervous system in survivors of childhood cancer: a report from the Childhood Cancer Survivor Study. J Natl Cancer Inst 2006:98:1528-37. doi:10.1093/inci/djij11.

43 Gurcay AG, Bozkurt I, Senturk S, et al. Diagnosis, treatment, and management strategy of meningioma during pregnancy. Asian Neurosurg 2018;13:86-9. doi:10.4103/1793-5482.181115.

44 Blitshteyn S, Crook JE, Jaeckle KA. Is there an association between meningioma and hormone replacement therapy?/ Clin Oncol 2008;26:279-82. doi:10.1200/JC0.2007.14.2133.

45 Lee E, Grutsch J, Persky V, Glick R, Mendes J, Davis F. Association of meningioma with reproductive factors. Int J Cancer 2006;119:1152 7. doi:10.1002/ijc.21950

46 Wigertz A, Lönn S, Mathiesen T, Ahlbom A, Hall P, Feychting M, Swedish Interphone Study Group. Risk of brain tumors associated with exposure to exogenous female sex hormones. Am J Epidemiol 2006;164:629-36. doi:10.1093/aje/kwj254.

47 Wigertz A, Lönn S, Hall P, et al. Reproductive factors and risk of meningioma and glioma. Cancer Epidemiol Biomarkers Prev 2008;17:2663-70. doi:10.1158/1055-9965.EPI-08-0406.

48 Chakravarthy V, Kaplan B, Gospodarev V, Myers H, De Los Reyes K, Achiriloaie A. Houdini tumor: case report and literature review of pregnancy-associated meningioma. World Neurosurg 2018;114:e1261-5. doi:10.1016/j.wneu.2018.03.187.

49 Hortobágyi T, Bencze J, Murnyák B, Kouhsari MC, Bognár L, MarkoVarga G. Pathophysiology of meningioma growth in pregnancy. Open Med (Wars) 2017:12:195-200. doi:10.1515/med-2017-0029.

50 Kerschbaumer J, Freyschlag CF, Stockhammer G, et al. Hormonedependent shrinkage of a sphenoid wing meningioma after pregnancy: case report. / Neurosurg 2016;124:137-40. doi:10.3171/2014.12.JNS142112.

51 Kubo M, Fukutomi T, Akashi-Tanaka S, Hasegawa T. Association of breast cancer with meningioma: report of a case and review of the literature. Jpn J Clin Oncol 2001;31:510-3. doi:10.1093/jico/ hye109.

52 Custer BS, Koepsell TD, Mueller BA. The association between breast carcinoma and meningioma in women. Cancer 2002;94:1626-35. doi:10.1002/cncr.10410

53 Benson VS, Pirie K, Green J, Casabonne D, Beral V, Million Women Study Collaborators. Lifestyle factors and primary glioma and meningioma tumours in the Million Women Study cohort. $\mathrm{Br}$ Cancer 2008;99:185-90. doi:10.1038/sj.bjc.6604445

54 Benson VS, Kirichek O, Beral V, Green J. Menopausal hormone therapy and central nervous system tumor risk: large UK prospective study and meta-analysis. Int J Cancer 2015;136:2369-77. doi:10.1002/ijc.29274.
55 Donnell MS, Meyer GA, Donegan WL. Estrogen-receptor protein in intracranial meningiomas. J Neurosurg 1979;50:499-502. doi:10.3171/jns.1979.50.4.0499.

56 Poisson M, Magdelenat H, Foncin JF, et al. Récepteurs d'oestrogènes et de progestérone dans les méningiomes. Etude de 22 cas. Rev Neurol (Paris) 1980;136:193-203.

57 Maiuri F, Montagnani S, Gallicchio B. Estrogen and progesterone receptors in meningiomas. Surg Neurol 1986;26:435-40 doi:10.1016/0090-3019(86)90255-7

58 Goffin J. Estrogen- and progesterone-receptors in meningiomas. Clin Neurol Neurosurg 1986;88:169-75. doi:10.1016/S03038467(86)80024-5

59 Omulecka A, Papierz W, Nawrocka-Kunecka A, Lewy-Trenda I. Immunohistochemical expression of progesterone and estrogen receptors in meningiomas. Folia Neuropathol 2006;44:111-5.

60 Bouillot P, Pellissier JF, Devictor B, et al. Quantitative imaging of estrogen and progesterone receptors, estrogen-regulated protein, and growth fraction: immunocytochemical assays in 52 meningiomas. Correlation with clinical and morphological data. Neurosurg 1994;81:765-73. doi:10.3171/ins.1994.81.5.0765.

61 Ülgen E, Bektaşoğlu PK, Sav MA, et al. Meningiomas display a specific immunoexpression pattern in a Rostrocaudal gradient: an analysis of 366 patients. World Neurosurg 2019;123:e520-35. doi:10.1016/i. wneu.2018.11.201.

62 Peyre M, Gaillard S, de Marcellus C, et al. Progestin-associated shift of meningioma mutational landscape. Ann Oncol 2018;29:681-6. doi:10.1093/annonc/mdx763.

63 HAS. Commission De La Transparence Avis 19 décembre 2012 Examen du dossier des spécialités inscrites pour une durée de 5 ans à compter du 31 décembre 2005 (J0 du 3 août 2007) Androcur 50 mg, comprimé sécable B/ 20 (CIP: 323 510-0) Androcur 100 mg, comprimé sécable B/ 60 (CIP : 340 417-5) Laboratoires Bayer Sante. 2012. https://www.has-sante.fr/upload/docs/evamed/CT-10007 ANDROCUR_Avis2_CT10007_RI_PIS.pdf

64 HAS. Commission De La Transparence Avis 22 juin 2016 acétate de cyprotérone Androcur 50 mg, comprimé sécable B/ 20 (CIP: 34009 3235100 8) Androcur 100 mg, comprimé sécable B/60 (CIP: 340093404175 4). 2016. https://www.has-sante.fr/upload/docs/ evamed/CT-14651_ANDROCUR_PIS_RI_Avis2_CT14651.pdf

65 Agence nationale de sécurité du médicament et des produits de santé (ANSM). Source OCTAVE. 2019

66 Bernat AL, Bonnin S, Labidi M, et al. Regression of giant olfactory groove meningioma and complete visual acuity recovery after discontinuation of cyproterone acetate. J Ophthalmic Vis Res 2018;13:355-8. doi:10.4103/jovr.jovr_21_17.

67 van der Vossen S, Schepers VPM, Berkelbach van der Sprenkel JW, Visser-Meily JM, Post MW. Cognitive and emotional problems in patients after cerebral meningioma surgery. J Rehabil Med 2014:46:430-7. doi:10.2340/16501977-1795.

68 Goldbrunner R, Minniti G, Preusser M, et al. EANO guidelines for the diagnosis and treatment of meningiomas. Lancet Oncol 2016;17:e383-91. doi:10.1016/S1470-2045(16)30321-7.

69 Coste J. Diverging approaches of pharmacovigilance and pharmacoepidemiology to assessing drug safety: epistemological and ethical implications. Pharmacoepidemiol Drug Saf 2017:26:600-2. doi:10.1002/pds.4190.

70 ANSM. Meningioma and cyproterone acetate temporary specialized scientific committee (CSST) report to the Agence nationale de sécurité du médicament et des produits de santé (French National Agency for Medicines and Health Products Safety). 2018. https:// ansm.sante.fr/S-informer/Points-d-information-Points-d-information Androcur-et-generiques-acetate-de-cyproterone-50-mg-et-100-mget-risque-de-meningiome-I-ANSM-publie-des-recommandationspour-la-prise-en-charge-des-patients-Point-d-information

71 European Medicines Agency. Meeting highlights from the Pharmacovigilance Risk Assessment Committee (PRAC) 10-13 February 2020. https://www.ema.europa.eu/en/news/meeting highlights-pharmacovigilance-risk-assessment-committee-prac-1013-february-2020

72 Champagne P-O, Passeri T, Froelich S. Combined hormonal influence of cyproterone acetate and nomegestrol acetate on meningioma: a case report. Acta Neurochir (Wien) 2019;161:589-92. doi:10.1007/ s00701-018-03782-4.

73 Passeri T, Champagne P-O, Bernat A-L, et al. Spontaneous regression of meningiomas after interruption of nomegestrol acetate: a series of three patients. Acta Neurochir (Wien) 2019;161:761-5. doi:10.1007/s00701-019-03848-x.

74 Shimizu J, Matsumoto M, Yamazaki E, Yasue M. Spontaneous regression of an asymptomatic meningioma associated with discontinuation of progesterone agonist administration. Neurol Med Chir (Tokyo) 2008;48:227-30. doi:10.2176/nmc.48.227

Web appendix: Supplementary material 